\title{
Body composition changes during and after curative chemotherapy in patients with testicular cancer
}

\author{
Otakar Semerad ${ }^{\mathrm{a}}$, Tomas Buchler ${ }^{\mathrm{b}}$, Jiri Vejmelka ${ }^{\mathrm{a}}$, Aneta Rozsypalova ${ }^{\mathrm{b}}$, Jitka Tomesova ${ }^{\mathrm{c}}$, Pavel Kohout ${ }^{\mathrm{a}}$
}

\begin{abstract}
Background. Testicular cancer is associated with excellent prognosis and cure is achieved in most patients with advanced cancer treated with cisplatin-based chemotherapy. However, testicular cancer survivors are at increased risk of accelerated atherosclerosis, which significantly contributes to their late morbidity and mortality. Atherosclerosis is associated with a higher proportion of fat mass and especially with increased amount of visceral fat. We explored the effects of cisplatin-based chemotherapy on body composition during and after the treatment.

Patients and Methods. We studied 30 testicular cancer patients before chemotherapy, after the second cycle of chemotherapy and three months after the end of chemotherapy. Body composition parameters were evaluated using bioelectrical impedance analysis (BIA).

Results. Three months after the end of chemotherapy the fat mass had increased from $22.04 \pm 7.15 \%$ to $23.92 \pm 7.33 \%$ $(P=0.026)$ and visceral fat volume had increased by $17 \%$ from $2.36 \pm 1.75 \mathrm{I}$ to $2.77 \pm 1.94 \mathrm{I}(P=0.013)$. In the whole sample there was a decrease in muscle mass after the second cycle of chemotherapy $(-1.33 \pm 2 \mathrm{~kg}$ on average; $P=0.005)$. The changes in body composition varied according to distinct baseline fat mass.

Conclusion. Cisplatin-based chemotherapy was associated with increase of fat mass, visceral fat, and body mass index. We also observed decrease in muscle mass and total body water. Our results suggest that BIA could help to target preventative measures to avert the acceleration of atherosclerosis in patients treated with cisplatin-based chemotherapy.
\end{abstract}

Key words: testicular cancer, chemotherapy, bioelectrical impedance analysis, body composition, fat mass

Received: September 17, 2020; Revised: November 18, 2020; Accepted: November 23, 2020; Available online: December 15, 2020 https://doi.org/10.5507/bp.2020.058

(c) 2022 The Authors; https://creativecommons.org/licenses/by/4.0/

${ }^{a}$ Department of Internal Medicine, Third Faculty of Medicine, Charles University and Thomayer Hospital, Prague, Czech Republic ${ }^{b}$ Department of Oncology, First Faculty of Medicine, Charles University and Thomayer Hospital, Prague, Czech Republic 'Nutrition Centre, Thomayer Hospital, Prague, Czech Republic

Corresponding author: Pavel Kohout, e-mail: pavel.kohout@ftn.cz

\section{INTRODUCTION}

Testicular germ-cell tumours (TGCT) are diagnosed in approximately 500 men in the Czech Republic every year ${ }^{1}$. It is the most common tumour of men aged 15 to 40 years $^{2}$. More than $90 \%$ of all patients achieve longterm survival ${ }^{3}$. Non-oncological complications such as accelerated atherosclerosis significantly contribute to late morbidity and mortality of patients with the history of TGCT $\left(\right.$ ref. $\left.^{49}\right)$. A double or higher risk of cardiovascular disease has been observed in long-term survivors ${ }^{8,10}$. The problem is currently not receiving enough attention during the long-term follow-up of these patients by urologists, oncologists, or general practitioners. Therefore, an active approach to identify and treat long-term complications together with lifestyle adjustments could significantly reduce post-therapeutic morbidity and mortality in this population.

The higher incidence of atherosclerotic complications during long-term observation is phenomenon that has not been fully explained yet. Patients after chemotherapy containing cisplatin had significant increase in the BMI and a higher prevalence of obesity $y^{6,7,9,11-13}$. Bleomycin and cisplatin are known to induce endothelial damage ${ }^{14}$. Fatfree mass (FFM) decline is associated with loss of muscle strength, immune, pulmonary, and cardiac function ${ }^{15}$. Changes in body fat content are not routinely measured in these patients as a part of follow-up. Subjective methods of nutritional assessment such as questionnaires do not provide information about body composition. Bipedal bioelectric impedance is a simple, non-invasive method for assessing body composition which has already been used in cancer patients. It is well suited for longitudinal monitoring of changes in fat/water content during cancer treatment ${ }^{16}$. The aim of this study is to evaluate the change in body composition using BIA with a focus on fat mass in patients with testicular tumours during and after chemotherapy.

\section{PATIENTS AND METHODS}

This study enrolled men starting chemotherapy for advanced TGCT at the Department of Oncology, First Faculty of Medicine of Charles University and Thomayer Hospital since November 2016 to October 2018. The participants had histologically confirmed testicular tumour to be treated with chemotherapy.

The bleomycin/etoposide/cisplatin (BEP) chemotherapy protocol was used with curative intentions in all pa- 
tients following radical orchidectomy. For etoposide, the dose was $100 \mathrm{mg} / \mathrm{m}^{2}$ and for cisplatin $20 \mathrm{mg} / \mathrm{m}^{2}$ on days 1-5 in each chemotherapy cycle. For bleomycin, the fixed dose was used $30 \mathrm{mg}$ on day 1,8 , and 15 of each cycle ${ }^{17}$.

To measure changes in body composition the Medical Body Composition Analyzer Seca 515 (Seca mBCA 515) was used. An 8-point bioelectric impedance analysis was performed at a frequency range of $5-50 \mathrm{kHz}$ with an electric current of $100 \mu \mathrm{A}$. The weight was determined by the scale integrated in the Seca mBCA 515. The height was determined by a standardized technique with a metal stadiometer with an accuracy of $1 \mathrm{~mm}$. Seca analytics 115 software was used to analyse the data. The measurements were performed according to the NIHR Southampton Biomedical Research Centre standard protocol ${ }^{18}$.

The output of each measurement was basic anthropometric data such as height, weight, and waist circumference. BMI was calculated as weight (kilograms) divided by height $\left(\right.$ meters $\left.^{2}\right)$. Furthermore, bioimpedance analysis data include fat-mass and fat-free mass, muscle mass, total body water and its extracellular fraction, basal metabolism, and phase angle. BIA measurements were performed before the start of chemotherapy, after the second cycle of chemotherapy and then 3 months after the end of chemotherapy. Patients who did not undergo all 3 planned BIA measurements were excluded from the evaluation of changes in body composition. Student t-tests were used to assess the significance of changes in parameters obtained from BIA. The summary statistics are presented as means and standard deviation. In all tests a $P<0.05$ was considered as significant.

\section{RESULTS}

Thirty men with newly diagnosed testicular tumour participated in the study. Patients with a history of cancer and chemotherapy were excluded. The mean age of patients was 37 years and ranged from 22 to 60 years. The race of all patients participating in the study was Caucasian. Histopathology of the tumour showed seminoma in six patients ( $20 \%$ of the cohort) and nonseminoma in 24 patients ( $80 \%$ of the cohort) (Table 1 ). Three cycles of chemotherapy were most frequently used (14 patients), 9 patients underwent 4 cycles of chemotherapy and in 7 patients only 2 cycles of chemotherapy were applied.

Twenty-three patients out of 30 enrolled in the study underwent 3 planned measurements due to the length of the study, limited patient compliance, and health problems not related to underlying cancer. Data from these 23 patients were used to assess changes in body composition. The evaluable cohort of 23 patients was divided in two groups according to the initial representation of fat mass (FM) (group A and group B). The discriminatory value for the inclusion of patients in these two groups was $20 \%$ of FM found at the first BIA measurement, before the start of chemotherapy. Group A included patients with FM over $20 \%$ (13 patients). Group B included patients whose FM was under 20\% (10 patients). Values over three measurements are reported generally for the entire patient population $(n=23)$ and separately for group $A(n=13)$ and B $(n=10)$. Data obtained by BIA are shown in Table 2 and will be commented in more detail below.

We used bioelectrical impedance analysis to detect changes in body composition during cancer treatment. We

Table 1. Characteristics of study participants.

\begin{tabular}{|c|c|c|c|}
\hline & & Number & $\%$ \\
\hline Mean age $(n=30)$ & 37 years & & \\
\hline \multirow{3}{*}{$\begin{array}{l}\text { Number of cycles } \\
\text { of chemotherapy }(n=30)\end{array}$} & 4 cycles & 9 & 30 \\
\hline & 3 cycles & 14 & 47 \\
\hline & 2 cycles & 7 & 23 \\
\hline \multirow[t]{3}{*}{ Smoking status $(\mathrm{n}=28)$} & smoker & 5 & 18 \\
\hline & ex-smoker & 9 & 32 \\
\hline & non-smoker & 14 & 50 \\
\hline \multirow{2}{*}{ Arterial hypertension $(\mathrm{n}=28)$} & yes & 7 & 25 \\
\hline & no & 21 & 75 \\
\hline \multirow[t]{2}{*}{ Diabetes mellitus $(\mathrm{n}=28)$} & yes & 1 & 4 \\
\hline & no & 27 & 96 \\
\hline \multirow[t]{2}{*}{ Dyslipidemia $(\mathrm{n}=28)$} & yes & 7 & 25 \\
\hline & no & 21 & 75 \\
\hline \multirow[t]{2}{*}{$\begin{array}{l}\text { Histological type of tumour } \\
(\mathrm{n}=30)\end{array}$} & $\begin{array}{l}\text { seminomatous } \\
\text { germ-cell tumour }\end{array}$ & 6 & 20 \\
\hline & $\begin{array}{l}\text { non-seminomatous } \\
\text { germ-cell tumour }\end{array}$ & 24 & 80 \\
\hline \multirow[t]{3}{*}{ Stage } & I & 7 & 30.4 \\
\hline & II & 9 & 39.1 \\
\hline & III & 7 & 30.4 \\
\hline
\end{tabular}


observed significant weight gain $(+3.03 \pm 4 \mathrm{~kg} ; P=0.001)$ three months after the completion of chemotherapy in the whole sample. Interestingly, patients in group A achieved more than threefold weight gain $(+4.63 \pm 4.03$ $\mathrm{kg} ; P=0.001)$ compared to patients in group $\mathrm{B}(+0,96 \pm$ $3 \mathrm{~kg} ; P=0.34$ ) (Fig. 1). Along with the weight gain, BMI also increased during the study. There was a shift from initial BMI $26.65 \pm 3.98$ to $27.19 \pm 4.19(P=0.046)$ at the end of the study in the whole cohort. The number of obese patients increased by $50 \%$ in the time of third measurement compared to the initial number.

In the whole cohort, the proportion of fat body mass increased during each BIA measurement. Patients in the whole sample gain $+1.88 \pm 3.70 \%(P=0.026)$ of fat mass between the first and third measurement. We also observed differences in timing of fat mass gain. In group A there was a maximal increase between the second and the third measurement. On the contrary, in group B, maximal increase in the proportion of fat body mass occurred between the first and second measurement $+2.7 \pm 1.68 \%$ $(P=0.002)$ (Fig. 2).

The increase in visceral fat was even more pronounced than the increase of the fat mass. The amount of visceral fat rose by $17 \%$ between the first and third measurement in the whole sample. In group A, we observed continual increase of visceral fat. In group $B$, there was a significant increase $(+0.4 \pm 0.21 ; P=0.0002)$ between first and second BIA but insignificant decrease in the amount of visceral fat between second and third measurement. Changes in waist circumference correlated with development in visceral fat.

Another parameter we monitored was muscle mass. In the whole sample we observed a decrease in muscle mass between the first and second measurement (mean difference $-1.33 \pm 2 \mathrm{~kg} ; P=0.005$ ). The loss of muscle mass was measured in 17 out of 23 patients. The decrease of muscle mass was more pronounced in the group B. We observed restoration of muscle mass with mean difference $+1.18 \pm 2.16 \mathrm{~kg}(P=0.018)$ between the second and third measurement in the whole sample. However, patients in group B did not achieve the muscle mass values they had prior to chemotherapy, even three months after the end of the treatment. Despite the decrease in muscle mass during chemotherapy, none of the patients deteriorated to sarcopenia. Sarcopenia cut-off point for men was established as ASM $/$ hight $^{2}<7.0 \mathrm{~kg} / \mathrm{m}^{2}$ according to Gould et al. ${ }^{19}$ (Fig. 3).

The relative amount of total body water was gradually decreasing in all three BIA measurements in the whole sample. The most significant decrease was in group B between the first and second measurement $(-2.03 \pm 1.5 \%$; $P=0.002$ ).

\section{DISCUSSION}

In a cohort of TGCT patients treated with cisplatinbased chemotherapy, we observed a significant increase of fat mass, visceral fat, and BMI three months after the initiation of chemotherapy compared to the initial

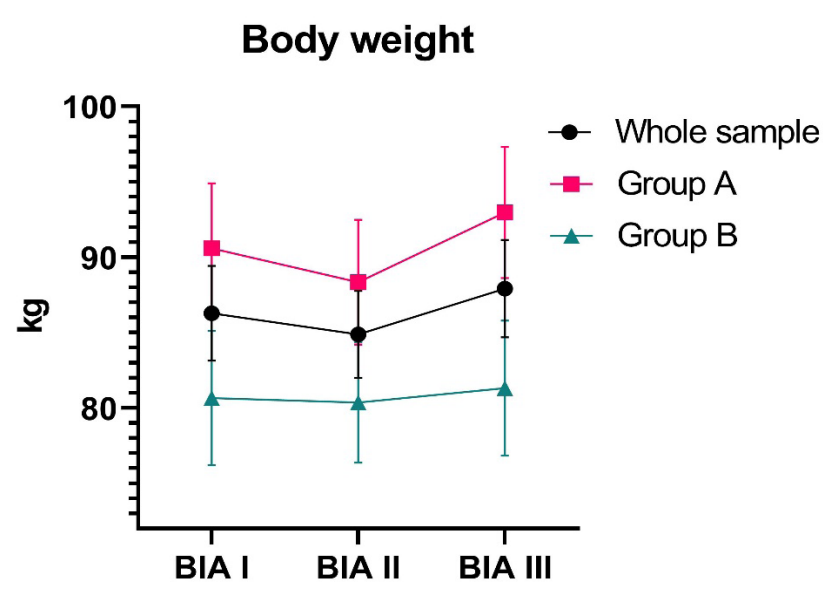

Fig. 1. Average weight change during the measurement. Data and error bars represent the mean \pm SEM.

\section{Fat mass}

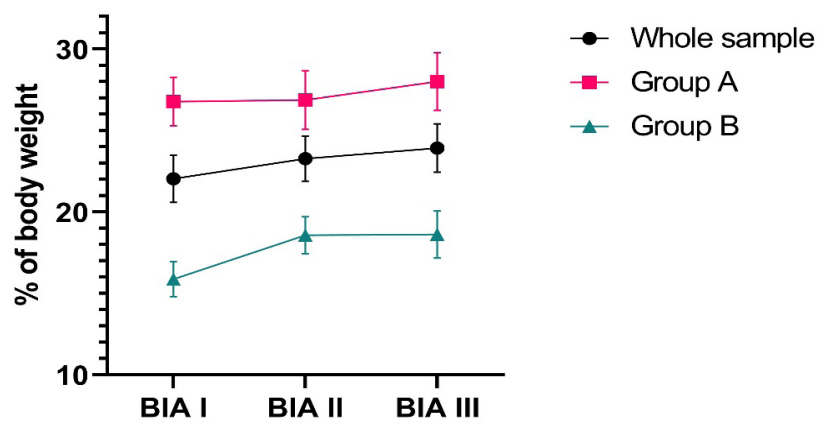

Fig. 2. The average change in the proportion of fat mass during the measurement. Data and error bars represent the mean \pm SEM.

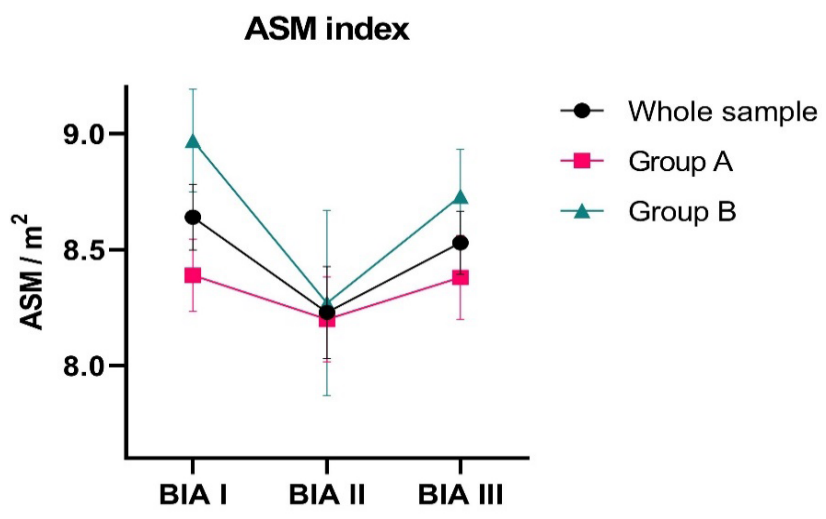

Fig. 3. Mean change in appendicular skeletal mass index $\left(\mathrm{ASM} / \mathrm{m}^{2}\right)$ during BIA measurements. Data and error bars represent the mean \pm SEM.

measurement. There was also a concomitant significant decrease in muscle mass and total body water after the second cycle of chemotherapy compared to initial values.

In comparison to the general population, the TGCT survivors have significantly higher risk of several late cancer and non-oncological complications. Patients receiving cisplatin-based chemotherapy regimens are at increased 
Table 2. Changes in body composition in patients with testicular tumours undergoing chemotherapy. All measured values are expressed as mean \pm standard deviation.

\begin{tabular}{|c|c|c|c|c|c|c|c|}
\hline & & $1^{\text {st }} \mathrm{BIA}$ & $\begin{array}{l}1^{\text {st }} \text { BIA } \\
\text { versus } \\
2^{\text {nd }} B I A, \\
P \text { value }\end{array}$ & $2^{\text {nd }} B I A$ & $\begin{array}{l}2^{\text {nd }} \text { BIA } \\
\text { versus } \\
3^{\text {rd }} B I A, \\
P \text { value }\end{array}$ & $3^{\text {rd }}$ BIA & $\begin{array}{l}1^{\text {st }} \text { BIA } \\
\text { versus } \\
3^{\text {rd }} \text { BIA, } \\
P \text { value }\end{array}$ \\
\hline \multirow[t]{3}{*}{ Body weight (kg) } & Whole cohort & $86.28 \pm 15.44$ & 0.078 & $84.88 \pm 14.22$ & 0.001 & $87.91 \pm 15.83$ & 0.062 \\
\hline & Group A & $90.6 \pm 15.52$ & 0.052 & $88.35 \pm 14.9$ & 0.001 & $92.97 \pm 15.66$ & 0.087 \\
\hline & Group B & $80.67 \pm 14.11$ & 0.784 & $80.37 \pm 12.59$ & 0.337 & $81.33 \pm 14.17$ & 0.492 \\
\hline \multirow[t]{3}{*}{ Waist circumference $(\mathrm{cm})$} & Whole cohort & $93.57 \pm 12.74$ & 0.084 & $95.02 \pm 12.11$ & 0.685 & $95.48 \pm 13.84$ & 0.090 \\
\hline & Group A & $100.27 \pm 11.71$ & 0.488 & $101 \pm 12.12$ & 0.516 & $102.08 \pm 13.74$ & 0.352 \\
\hline & Group B & $84.85 \pm 8.04$ & 0.096 & $87.25 \pm 6.61$ & 0.823 & $86.9 \pm 8.49$ & 0.018 \\
\hline \multirow[t]{3}{*}{ Visceral fat (1) } & Whole cohort & $2.36 \pm 1.75$ & 0.014 & $2.62 \pm 1.78$ & 0.281 & $2.77 \pm 1.94$ & 0.013 \\
\hline & Group A & $3.36 \pm 1.71$ & 0.374 & $3.51 \pm 1.9$ & 0.206 & $3.78 \pm 1.93$ & 0.113 \\
\hline & Group B & $1.06 \pm 0.54$ & 0.0002 & $1.46 \pm 0.57$ & 0.953 & $1.45 \pm 0.89$ & 0.029 \\
\hline \multirow[t]{3}{*}{ Fat mass $(\%)$} & Whole cohort & $22.04 \pm 7.15$ & 0.046 & $23.27 \pm 6.79$ & 0.294 & $23.92 \pm 7.33$ & 0.026 \\
\hline & Group A & $26.78 \pm 5.38$ & 0.919 & $26.87 \pm 6.52$ & 0.241 & $28 \pm 6.41$ & 0.329 \\
\hline & Group B & $15.88 \pm 3.42$ & 0.001 & $18.58 \pm 3.6$ & 0.959 & $18.62 \pm 4.62$ & 0.017 \\
\hline \multirow[t]{3}{*}{ Fat-free mass (\%) } & Whole cohort & $77.96 \pm 7.15$ & 0.046 & $76.73 \pm 6.79$ & 0.294 & $76.08 \pm 7.33$ & 0.026 \\
\hline & Group A & $73.22 \pm 5.38$ & 0.916 & $73.13 \pm 6.52$ & 0.241 & $72 \pm 6.41$ & 0.329 \\
\hline & Group B & $84.12 \pm 3.42$ & 0.001 & $81.42 \pm 3.6$ & 0.959 & $81.38 \pm 4.62$ & 0.017 \\
\hline \multirow[t]{3}{*}{ Muscle mass (kg) } & Whole cohort & $32.67 \pm 4.59$ & 0.005 & $31.34 \pm 4.65$ & 0.018 & $32.51 \pm 4.21$ & 0.643 \\
\hline & GroupA & $32.27 \pm 3.83$ & 0.058 & $31.33 \pm 3.72$ & 0.039 & $32.52 \pm 3.96$ & 0.441 \\
\hline & Group B & $33.19 \pm 5.6$ & 0.044 & $31.35 \pm 5.86$ & 0.206 & $32.51 \pm 4.74$ & 0.294 \\
\hline \multirow[t]{3}{*}{ BMI $\left(\mathrm{kg} / \mathrm{m}^{2}\right)$} & Whole cohort & $26.65 \pm 3.98$ & 0.161 & $26.3 \pm 3.70$ & 0.002 & $27.19 \pm 4.19$ & 0.046 \\
\hline & Group A & $28.52 \pm 3.83$ & 0.141 & $27.96 \pm 3.64$ & 0.002 & $29.30 \pm 3.85$ & 0.083 \\
\hline & Group B & $24.21 \pm 2.73$ & 0.805 & $24.14 \pm 2.6$ & 0.291 & $24.45 \pm 2.88$ & 0.347 \\
\hline \multirow[t]{3}{*}{ Total body water (1) } & Whole cohort & $48.70 \pm 6.45$ & 0.020 & $47.33 \pm 5.67$ & 0.040 & $48.37 \pm 5.85$ & 0.533 \\
\hline & Group A & $48.10 \pm 5.16$ & 0.220 & $47.11 \pm 5.31$ & 0.110 & $48.46 \pm 5.44$ & 0.529 \\
\hline & Group B & $49.48 \pm 8.06$ & 0.060 & $47.61 \pm 6.39$ & 0.190 & $48.26 \pm 6.64$ & 0.205 \\
\hline \multirow[t]{3}{*}{ Total body water (\%) } & Whole cohort & $56.70 \pm 5.10$ & 0.100 & $55.93 \pm 4.78$ & 0.250 & $55.35 \pm 5.27$ & 0.769 \\
\hline & Group A & $53.31 \pm 3.85$ & 0.760 & $53.49 \pm 3.75$ & 0.160 & $52.38 \pm 4.73$ & 0.337 \\
\hline & Group B & $61.12 \pm 2.34$ & 0.002 & $59.09 \pm 2.44$ & 0.850 & $59.20 \pm 3.01$ & 0.864 \\
\hline
\end{tabular}

risk of hypertension, hyperlipidemia, obesity, metabolic syndrome, and their consequences in the form of myocardial infarction or stroke ${ }^{4}$. The risk of cardiovascular complications is the highest in patients diagnosed and treated before the age of $35\left(\right.$ ref. $\left.^{20}\right)$. Patients treated with bleomycin, etoposide, cisplatin (BEP) chemotherapy had a 3.1 times higher risk of myocardial infarction compared to the control population ${ }^{11}$.

We found that patients with TGCT had significant weight gain between the second and third BIA measurement. Weight gain after chemotherapy has been also described by Freedman et al. ${ }^{21}$ in breast cancer patients receiving chemotherapy. In our study the separate evaluation of two patient groups with different initial FM revealed difference in body composition changes due to chemotherapy between those two groups. Patients in high initial FM (group A) achieved more than threefold weight gain compared to patients with low initial FM (group B). This trend may potentially lead to long-term adverse health effects in high FM patients, including a shift to obesity and its metabolic consequences. Obesity is a major contributor to cardiovascular disease, hypertension and stroke $^{22}$. In concordance with weight gain, the BMI values significantly increased three months after chemotherapy in the whole sample. The number of obese patients at the end of the study was $50 \%$ higher than at baseline.

In the whole sample, the proportion of fat body mass increased during the study. Similar change of body composition was observed in study of Freedman et. al. ${ }^{21}$ as well. In case of our patients we also observed difference in timing of fat mass gain. While stabilization and possible return to the original favourable body composition can be expected based on the observed trend in group B patients, an adverse metabolic effect may result in group A patients, where the adipose tissue growth accelerated during three months after the end of the chemotherapy.

Visceral fat mass has been shown to be metabolically active and is identified as a major factor to adverse effects on glucose and lipid metabolism, and endothelial dysfunction $^{23,24}$. Visceral fat expresses more inflammatory cytokines than subcutaneous fat. Increased amount of visceral fat may contribute to chronic low grade, systemic, inflammatory state. The inflammation triggered by adipose tissue may also lead to increased occurrence of vascular diseases ${ }^{25}$. The consequences of atherosclerosis contribute significantly to the mortality and morbidity of patients after successful TGCT treatment. Our results show that, the amount of visceral fat increased in all three measurements in the whole sample. 
Loss of muscle mass represents an accurate prognostic factor for augmented treatment toxicity, worsened outcomes, and overall reduced survival in cancer patients ${ }^{26}$. In the whole sample there was a decrease in muscle mass between the first and second measurement, although not reaching the sarcopenia threshold. This is most likely because the study included relatively young patients with high initial muscle mass.

In the whole sample mean of total body water decreased between the first and the second measurement. This might be caused by cisplatin nephrotoxicity. Cisplatin nephrotoxicity is a result of the transport of cisplatin into renal epithelial cells, damage of nuclear and mitochondrial DNA, activation of multiple cell death pathways and initiation of an inflammatory response $\mathrm{e}^{27}$. Polyuria is commonly associated with cisplatin nephrotoxicity ${ }^{28}$. In the third measurement, the lower proportion of total body water was more affected by increase of body fat mass.

Our study shows significant changes in the body composition in patients with TGCT treated with cisplatinbased chemotherapy. However, one of the limitations of this single centre study is the relatively small number of patients. We did not perform BIA measurement at similar time points in healthy controls. The design of the study thus precluded to differentiate between effects of treatment and time. Although chemotherapy is highly likely the cause of observed changes in body composition, we cannot with certainty differentiate between effects mediated by chemotherapy and changes in lifestyle, food intake, or corticosteroids treatment (as part of the anti-emetic regimen). However, the relatively low doses of steroids and the absence of their administration after the end of chemotherapy suggest that their effect on the change in body composition was not significant.

\section{CONCLUSION}

The standard treatment of testicular cancer patients with BEP chemotherapy leads to early loss of muscle mass and total body water. The simultaneous increase in fat mass and visceral fat gradually becomes more pronounced with longer time interval after the end of chemotherapy. These changes in body composition are related to the initial FM. Patients with high baseline FM are more likely to develop adverse changes in body composition after the chemotherapy and might have a higher incidence of atherosclerosis complications in the future. Preventive measures based on the results of BIA can help to avoid risk of these negative effects.

A prospective study in larger group of patients with a longer follow-up period will clarify whether adverse changes in body composition measured early after chemotherapy correlate with the incidence of future atherosclerotic complications.

\section{ABBREVIATIONS}

TGCT, Testicular germ-cell tumours; BEP, Bleomycin, etoposide, cisplatin; FFM, Fat-free mass; FM, Fat mass; BMI, Body mass index; ASM, Appendicular skeletal muscle mass; SD, Standard deviation; BIA, Bioelectrical impedance analysis; SEM, Standard error of the mean.

Acknowledgment: We gratefully acknowledge the support of Nutricia a. s., which provided the Seca mBCA 515 for bioimpedance analysis.

Author contributions: OS: manuscript writing, data analysis; PK, TB: study design, manuscript writing; JV: manuscript preparation; AR: data collection; JT: performing BIA measurements; All authors have edited and approved the final version of the manuscript.

Conflict of interest statement: The authors state that there are no related conflicts of interest.

\section{REFERENCES}

1. Dušek L, Mužík J, Gelnarová E, Fínek J, Vyzula R, Abrahámová J. Cancer Incidence and Mortality in the Czech Republic. Klin Onkol 2010;23(5):311-24.

2. Chia VM, Quraishi SM, Devesa SS, Purdue MP, Cook MB, McGlynn KA International trends in the incidence of testicular cancer, 1973-2002. Cancer Epidemiol Biomarkers Prev 2010;19(5):1151-9.

3. Hashibe M, Abdelaziz S, Al-Temimi M, Fraser A, Boucher KM, Smith $\mathrm{K}$, et al. Long-term health effects among testicular cancer survivors. J Cancer Surviv 2016;10(6):1051-7.

4. Meinardi MT, Gietema JA, van der Graaf WT, van Veldhuisen DJ, Runne MA, Sluiter WJ, Willemse PB, Mulder NH, van den Berg MP, Schraffordt H, Sleijfer DT. Cardiovascular morbidity in long-term survivors of metastatic testicular cancer. J Clin Oncol 2000;18(8):172532.

5. Nuver J, Smit AJ, Wolffenbuttel BH, Sluiter WJ, Hoekstra HJ, Sleijfer DT, Gietema JA. The metabolic syndrome and disturbances in hormone levels in long-term survivors of disseminated testicular cancer. J Clin Oncol 2005; 23(16):3718-25.

6. Nord C, Fosså SD, Egeland T. Excessive annual BMI increase after chemotherapy among young survivors of testicular cancer. Br J Cancer 2003;88(1):36-41.

7. Sagstuen H, Aass N, Fosså SD, Dahl O, Klepp O, Wist EA, Wilsgaard $\mathrm{T}$, Bremnes RM. Blood pressure and body mass index in long-term survivors of testicular cancer. J Clin Oncol 2005;23(22):4980-90.

8. Huddart RA, Norman A, Shahidi M, Horwich A, Coward D, Nicholls J, Daernaly DP. Cardiovascular disease as a long-term complication of treatment for testicular cancer. J Clin Oncol 2003;21(8):1513-23 .

9. van Den Belt-Dusebout AW, Nuver J, de Wit R, Gietema JA, Ten Bokkel Huinink WW, Rodrigus PT, Schimmel EC, Aleman BM, Leeuven FE, Long-term risk of cardiovascular disease in 5-year survivors of testicular cancer. J Clin Oncol 2006;24(3):467-75.

10. Haugnes HS, Wethal T, Aass N, Dahl O, Klepp O, Langberg CW Wilsgaard T, Bremnes RM, Fossa SD. Cardiovascular risk factors and morbidity in long-term survivors of testicular cancer: A 20-year follow-up study. J Clin Oncol 2010;28(30):4649-57.

11. Vaughn DJ, Palmer SC, Carver JR, Jacobs LA, Mohler ER. Cardiovascular risk in long-term survivors of testicular cancer. Cancer 2008;112(9):1949-53.

12. Van Den Belt-Dusebout AW, De Wit R, Gietema JA, Horenblas S, Louwman MW, Ribot JG, Hoekstra HJ, Ouwens GM, Aleman BM, van Leeuwen FE. Treatment-specific risks of second malignancies and cardiovascular disease in 5-year survivors of testicular cancer. J Clin Oncol 2007;25(28):4370-8.

13. Bokemeyer C, Berger CC, Kuczyk MA, Schmoll HJ. Evaluation of longterm toxicity after chemotherapy fortesticular cancer. J Clin Oncol 1996;14(11):2923-32.

14. Nuver J, De Haas EC, Van Zweeden M, Gietema JA, Meijer C. Vascular 
damage in testicular cancer patients: A study on endothelial activation by bleomycin and cisplatin in vitro. Oncol Rep 2010;23(1):24753.

15. Halpern-Silveira D, Susin LR, Borges LR, Paiva SI, Assunção MC, Gonzalez MC. Body weight and fat-free mass changes in a cohort of patients receiving chemotherapy. Support Care Cancer 2010;18(5):617-25.

16. Isenring E, Bauer J, Capra S, Davies PS. Evaluation of foot-to-foot bioelectrical impedance analysis for the prediction of total body water in oncology outpatients receiving radiotherapy. Eur J Clin Nutr 2004;58(1):46-51.

17. Albers P, Albrecht W, Algaba F, Bokemeyer C, Cohn G, CedermarkCohn, Horwich A, Klepp O, Laguna MP, Pizzocaro G. European as sociation of urology, Guidelines EUS pro diagnostiku, klasifikaci a léčbu testikulárního karcinomu. Urol List 2006;4(3):61-86.

18. Bioelectrical impedance analysis measurement procedure by the Medical Body Composition Analyzer Seca 515. NIHR Southampton Biomedical Research Centre 2014, Available from: https://www. uhs.nhs.uk/Media/Southampton-Clinical-Research/Procedures/ BRCProcedures/Procedure-for-bioimpedance-using-the-SecamBCA.pdf

19. Gould H, Brennan SL, Kotowicz MA, Nicholson GC, Pasco JA. Tota and appendicular lean mass reference ranges for Australian men and women: The Geelong osteoporosis study. Calcif Tissue Int 2014;94(4):363-72

20. Fosså SD, Gilbert E, Dores GM, Chen J, McGlynn KA, Schonfeld S, Storm H, Hall $\mathrm{P}$, Holowaty $\mathrm{E}$, Andersen $\mathrm{A}$, Jonesuu $\mathrm{H}$, Andersson
M, Kajser M, Gospodarowicz M, Cohen R, Pukkala E, Travis LB. Noncancer causes of death in survivors of testicular cancer. J Natl Cancer Inst 2007;99(7):533-44.

21. Freedman RJ, Aziz N, Albanes D, Hartman T, Danforth D, Hill S, Sebring N, Reynolds JC, Yanovsky JA, Weight and Body Composition Changes during and after Adjuvant Chemotherapy in Women with Breast Cancer. J Clin Endocrinol Metab 2004;89(5):2248-53.

22. Head GA. Cardiovascular and metabolic consequences of obesity Front Physiol 2015;6:32.

23. Björntorp P. Metabolic implications of body fat distribution. Diabetes Care 1991;14(12):1132-43.

24. Brook RD, Bard RL, Rubenfire $M$, Ridker PM, Rajagopalan S. Usefulness of visceral obesity (waist/hip ratio) in predicting vascular endothelial function in healthy overweight adults. Am J Cardiol 2001;88(11):1264-9.

25. Öhman MK, Shen Y, Obimba Cl, Wright AP, Warnock M, Lawrence DA, Eitzman DT. Visceral adipose tissue inflammation accelerates atherosclerosis in apolipoprotein E-deficient mice. Circulation 2008;117(6):798-805

26. Pin F, Couch ME, Bonetto A. Preservation of muscle mass as a strategy to reduce the toxic effects of cancer chemotherapy on body composition. Curr Opin Support Palliat Care 2018;12(4):420-26.

27. Miller RP, Tadagavadi RK, Ramesh G, Reeves WB. Mechanisms of cisplatin nephrotoxicity. Toxins 2010;2(11):2490-518.

28. Arany I, Safirstein RL. Cisplatin nephrotoxicity. Semin Nephrol 2003;23(5):460-4 